\title{
Development and Effect of Information Program for Operating Room Nurses for Arteriovenous Fistula and Angioplasty Subject
}

\author{
Hea-Won Lee ${ }^{1}$ and Sung-Ju Park ${ }^{2}$ \\ ${ }^{1}$ Department of Nursing, The Graduate School of Public Health Nambu University, \\ Gwangju, Korea \\ ${ }^{2}$ Department of Nursing Science, Nambu University, Gwangju, Korea \\ ${ }^{2}$ psung3144@nambu.ac.kr
}

\begin{abstract}
The purpose of this study was to evaluate the effectiveness of preoperative and postoperative information provision programs by visiting operating room nurses in the hospital for the patients with end stage renal disease who underwent arteriovenous fistula and angioplasty. The subjects were 40 patients in the experimental group and 40 patients in the control group who were hospitalized for the arteriovenous fistula or angioplasty among patients undergoing dialysis with end-stage renal disease. Anxiety was measured by Spielberger, Kim and Shin using the standardized visual analog scale of the state anxiety tool and Cline, Herman, Shaw and Morton. Self-efficacy measures were developed by Sherer, Maddux, Jacobs and Rosers, and self-efficacy tools were used by Hong. The SPSS/WIN 21.0 program was used to analyze the demographic characteristics of the population, the preliminary homogeneity test for the general characteristics and dependent variables between the experimental group and the control group, the $x^{2}$ test and the $t$-test, the information of the operating room nurse. The t-test was used to measure differences in anxiety and self-efficacy between the experimental group and control group. Result, trait anxiety ( $t=2.31, p<.024)$, state anxiety $(t=10.18, p<.001)$ and self-efficacy $(t=-4.59, p<.001)$ in the experimental group receiving the information program of operating room nurse were significantly higher. The results of this study suggest that the information program of the nurses in the operating room reduces the anxiety of end-stage renal disease and improves the self-efficacy, and it can be used as training data for the patients who are scheduled for arteriovenous fistula and angioplasty.
\end{abstract}

Keywords: Information, Service, Program, End-stage, Renal, Disease, Patient, Anxiety, Self-efficacy

\section{Introduction}

Chronic disease patients have recently outnumbered acute disease patients, as Korea is rapidly entering an aging society resulting from the extension of average life expectancy due to the improvement and development of medical technologies [1]. End-stage renal disease is a condition in which the kidneys cannot function anymore, making it necessary for the patient to undergo a renal replacement therapy for life extension, such as dialysis therapy or kidney transplant. Patients who are being treated due to continuous reduction of renal function need

Article history:

Received (October 20, 2017), Review Result (December 18, 2017), Accepted (January 28, 2018) 
to secure a dialysis route suitable for hemodialysis; in this case, it is important to make a vascular access route by undergoing arteriovenous fistula surgery in advance after consulting a nephrologist. Surgery is an event that makes everyone feel a sense of crisis. Indeed, most of surgical patients take surgery itself seriously and feel anxiety due to postoperative pain, physical changes, uncertainty about the success of anesthesia and surgery, postoperative discomfort, separation from their family [2]. Such anxiety in surgical patients increases the activity of the autonomic nervous system, causing decreases in perceptive ability and concentration as well as reduction or loss of coping ability, which adversely affect the postoperative course and even the prognosis of recovery [3].

In that sense, it is necessary to provide patients with relevant information prior to surgery in order to reduce the anxiety of surgery. In general, the preoperative information given in the ward or outpatient clinic is mainly focused on physical aspects and follows task-based legal requirements and the hospital's perspective, instead of being patient-centered [4]. If the anesthesia room or operating room nurses, who are directly involved in each patient's surgery and nursing care, sufficiently inform and guide patients, this will create positive effects on the emotional state of patients scheduled to undergo surgery, thereby actually reducing their anxiety [5]. Kim [6] stated that the patient can gain psychological stability just with an operating room nurse's preoperative visit. Kim also asserted that operating room nurses' preoperative visit has a positive effect on the recovery of postoperative patients and reduces their anxiety and that the therapeutic interpersonal relationship and trust between patient and nurse, which is formed prior to surgery, also positively influences the quality of the nursing care provided during the period from the entry into the operating room to the stay in the recovery room [5].

Surgical information includes surgical methods, surgical procedures, anesthesia methods, self-care methods for the management of dialysis route, management methods for the prevention of complications, dietary therapy, exercise, etc. The patients who are provided with the information can relieve vague anxieties about future therapeutic methods and the future and strengthen their self-efficacy.

There are currently multiple previous studies to decrease surgical patients' anxiety through the information provision by operating room nurses; these studies are mostly focused on patients with total replacement arthroplasty [7], patients with total knee replacement arthroplasty [8], open-heart surgery patients [9], anxiety and stress by coping pattern [10], and cataract surgery patients [11]. However, research on end-stage renal disease patients who are scheduled to undergo the arteriovenous fistula surgery and angioplasty is still insufficient.

Therefore, this study aimed to develop a program of information provision by operating room nurses; apply it to end-stage renal disease patients who are scheduled to undergo surgery; and then identify the effects of the information provision program on patients' anxiety and self-efficacy. In this regard, the purpose of this study is to seek a nursing intervention method to enhance patients' self-efficacy by providing various pieces of information on dialysis vessel management and relevant methods, increase their quality of life by giving high-quality nursing services, and improve their health care.

\section{Research method}

\subsection{Design of study}

This study is a quasi-experiment by the non-equivalent control group pretest-posttest design, targeting patients undergoing the arteriovenous fistula surgery and angioplasty. This 
study was conducted to develop a program of information provision by operating room nurses and confirm the program provision's effects.

\subsection{Measurement tools}

The State Trait Anxiety Inventory (STAI) that was developed by Spielberger [12] and adapted by Kim and Shin [13], and the Visual Analogue Scale (VAS) standardized by Cline, Herman, Shaw, and Morton [14] were used as tools to measure anxiety. The measurement of self-efficacy involved using the Self-Efficacy Scale that was developed by Sherer, Maddux, Jacobs, and Rosers [15] and modified and adapted by Hong [16]. As for the reliability of these tools, Cronbach's $\alpha$ of trait anxiety was .89, and Cronbach's $\alpha$ of self-efficacy was .90 .

\subsection{Collection of data}

This study was conducted after the deliberation of research ethics and approval by the Institutional Review Board under N University. With regard to the effects of the information provision program by operating room nurses on patients, subjects were required to fill in preand post-operative questionnaires. The primary visit involved an investigator visiting the patient's room in the morning on the day of surgery and instructing the patient to fill in a questionnaire; and an operating room nurse providing necessary information. In the secondary visit undertaken a day after the surgery, the investigator provided necessary information and then instructed the patient to fill in a questionnaire. The completed questionnaires were kept at the ward and later collected by the investigator.

\subsection{Analysis of data}

The data collected in this study were analyzed using the SPSS/WIN 21.0 program. The normal distribution of data was analyzed with the Kolmognov-Smirnov test; the general characteristics of test and control groups and the pre-homogeneity test of dependent variables were with $X^{2}$-test and t-test; the general properties were with real numbers and percentage; and the effects of operating room nurses' information provision on anxiety and self-efficacy of end-stage renal disease patients were with t-test.

\section{Result}

\subsection{Development of the operating room nurse's information provision program}

In order to develop an information provision program for end-stage renal disease patients, this study was based on the five-step ADDIE Instructional Design Model including analysis, design, development, implementation, and evaluation, on the basis of the ADDIE Model, a representative model of Instructional Systems Development (ISD) [Table 1].

\subsubsection{Analysis stage}

Educational needs were analyzed based on previous studies, literature review, and interviews in order to develop an information provision program for end-stage renal disease patients.

\subsubsection{Design stage}

The draft of an information provision program was completed based on literature review and outcomes of the survey on educational needs. It was designed that visit would be 
undertaken two times in total: in the morning on the day of surgery and a day after the surgery, and the educational method would involve PPT and question and answer.

Table 1. Process of program development based on ADDIE instructional design model

\begin{tabular}{|c|c|c|}
\hline Stage & Detailed Activity & Project \\
\hline Analysis & $\begin{array}{l}\text { 1. Investigation of subjects' } \\
\text { needs } \\
\text { 2. Literature review }\end{array}$ & $\begin{array}{l}\text {. Face-to-face investigation } \\
\text {. Analysis and arrangement of educational contents }\end{array}$ \\
\hline Design & $\begin{array}{l}\text { 1. Setting of implementation } \\
\text { plans } \\
\text { 2. Selection of educational } \\
\text { contents } \\
\text { 3. Selection of educational } \\
\text { medium } \\
\begin{array}{l}\text { 4. Selection of evaluation } \\
\text { method }\end{array}\end{array}$ & $\begin{array}{c}\text {.Session 1: Visiting in the morning on the day of surgery } \\
\text { Education: } 30 \text { minutes } \\
\text { Question and answer: } 20 \text { minutes } \\
\text {. Session 2: Visiting a day after surgery } \\
\text { Education: } 30 \text { minutes } \\
\text { Question and answer: } 20 \text { minutes } \\
\text {.Exploration and selection of educational medium } \\
\text {.Completion of program }\end{array}$ \\
\hline Development & $\begin{array}{l}\text { 1. Verification of the program's } \\
\text { content validity } \\
\text { 2. Development of educational } \\
\text { materials }\end{array}$ & $\begin{array}{c}\text {.Verification of content validity by the specialist group } \\
\text { : One nephrologist } \\
\text { One vascular surgeon } \\
\text { Seven chief nurses } \\
\text { One director of nursing service } \\
\text {.Composed of a total of } 10 \text { specialists } \\
\text {.Development of program: completion of the PPT } \\
\text { educational material }\end{array}$ \\
\hline Implementation & $\begin{array}{l}\text { 1. Implementation of program } \\
\text { 2. Management of educational } \\
\text { subjects }\end{array}$ & $\begin{array}{l}\text {.Primary visit: } \\
\text { In the morning on the day of surgery } \\
\text { PPT education: } 30 \text { minutes } \\
\text { Question and answer: } 20 \text { minutes } \\
\text {. Secondary visit: } \\
\text { In the afternoon a day after surgery } \\
\text { PPT education: } 30 \text { minutes } \\
\text { Question and answer: } 20 \text { minutes }\end{array}$ \\
\hline Evaluation & $\begin{array}{l}\text { 1. Evaluation on the application } \\
\text { effects of the information } \\
\text { provision program } \\
\text { 2. Evaluation on the response } \\
\text { of educational subjects }\end{array}$ & . Check anxiety and self-efficacy of subjects. \\
\hline
\end{tabular}

\subsubsection{Development stage}

To verify the content validity, a total of 10 specialists composed of one nephrologist, one vascular surgeon, seven chief nurses with 15 or more years of clinical career, and one director of nursing service were involved in the verification process. As a result, as the CVI value was 1 (>0.8), the information provision program developed by the investigator turned out to be suitable as an educational material.

\subsubsection{Implementation stage}

The data collection was conducted over four months from June 20, 2017 to October 22, 2017. Before the initiation of this study, the approval from the Institutional Review Board was obtained, and the data collection was implemented in cooperation with the Nursing Department and chief nurses. 


\subsubsection{Evaluation stage}

The evaluation stage involved identifying the effects the program of information provision by operating room nurses had on anxiety, self-efficacy and nursing care satisfaction of endstage renal disease patients.

\subsection{Application effects of the information provision program by operating room nurses}

The differences in anxiety and self-efficacy between the test group who were offered the information provision program by operating room nurses and the control group are shown in [Table 2]. For anxiety, the trait anxiety scores in the test group and the control group were $1.90 \pm 0.54$ points and $2.52 \pm 0.47$ points, respectively, which indicates that the score was statistically significantly low in the test group $(\mathrm{t}=2.31, \mathrm{p}=.024)$. The state anxiety scores in the test group and the control group were $1.78 \pm 0.77$ points and $6.18 \pm 1.70$ points, respectively, showing that the score was statistically significantly low in the test group $(\mathrm{t}=10.18, \mathrm{p}<.001)$. In addition, the self-efficacy scores in the test group and the control group were $3.42 \pm 0.75$ points and $2.78 \pm 0.57$ points, respectively, and this suggests that the self-efficacy was statistically significantly higher in the test group $(\mathrm{t}=-4.59, \mathrm{p}=<.001)$.

Table 2. Differences in trait anxiety, state anxiety, self- efficacy between experimental and control groups $(\mathrm{N}=80)$

\begin{tabular}{|c|c|c|c|c|c|c|c|}
\hline \multirow{2}{*}{\multicolumn{2}{|c|}{ Variables }} & \multirow{2}{*}{ Groups } & Pre-test & Post-test & Difference & \multirow{2}{*}{$\mathrm{t}$} & \multirow{2}{*}{$\mathrm{p}$} \\
\hline & & & $\mathrm{M} \pm \mathrm{SD}$ & $\mathrm{M} \pm \mathrm{SD}$ & $\mathrm{M} \pm \mathrm{SD}$ & & \\
\hline \multirow{4}{*}{ Anxiety } & \multirow{2}{*}{ STAI } & Exp. $(n=40)$ & $2.91 \pm 0.73$ & $1.90 \pm 0.54$ & $-1.01 \pm 0.93$ & \multirow{2}{*}{2.31} & \multirow{2}{*}{.024} \\
\hline & & Con. $(n=40)$ & $3.10 \pm 0.57$ & $2.52 \pm 0.47$ & $-.59 \pm 0.67$ & & \\
\hline & \multirow{2}{*}{ VAS } & Exp. $(n=40)$ & $6.43 \pm 2.04$ & $1.78 \pm 0.77$ & $-4.65 \pm 2.03$ & \multirow{2}{*}{10.18} & \multirow{2}{*}{$<.001$} \\
\hline & & Con. $(n=40)$ & $6.95 \pm 1.89$ & $6.18 \pm 1.70$ & $-.78 \pm 1.29$ & & \\
\hline \multirow{2}{*}{\multicolumn{2}{|c|}{ Self - Efficacy }} & Exp. $(n=40)$ & $2.80 \pm 0.70$ & $3.42 \pm 0.75$ & $.62 \pm 0.68$ & -4.59 & $<.001$ \\
\hline & & Con. $(n=40)$ & $2.71 \pm 0.59$ & $2.78 \pm 0.57$ & $.07 \pm 0.34$ & & \\
\hline \multirow{2}{*}{\multicolumn{2}{|c|}{ Nursing -Satisfaction }} & Exp. $(n=40)$ & $2.18 \pm 0.74$ & $3.44 \pm 0.77$ & $1.26 \pm 0.84$ & -7.18 & $<.001$ \\
\hline & & Con. $(n=40)$ & $1.83 \pm 0.61$ & $2.00 \pm 0.82$ & $.17 \pm 0.48$ & - & - \\
\hline \multicolumn{8}{|c|}{ Exp. $=$ Experimental Group; Cont. $=$ Control Group } \\
\hline
\end{tabular}

\section{Conclusion}

This study was intended to develop an information provision program in which operating room nurses directly visit end-stage renal disease patients, who are scheduled to undergo arteriovenous fistula surgery and angioplasty, and provide relevant information; and to identify the effects of the program on them. As a result, it was found that the information provision program by operating room nurses was helpful in reducing the anxiety of end-stage renal disease patients, increasing their self-efficacy, and then improving their self-care ability. Further, such information provision contributed to promoting the quality of hospital services and enhancing patients' quality of life by offering the information suited for hospital patients' needs. In fact, it was rather difficult to conduct research on the nursing intervention for endstage renal disease patients because the sensitivity of subjects was high. However, it is unquestionable that these patients in clinical practices desperately need the support of medical 
personnel. Therefore, continuous medical personnel's more active studies and intervention on the patients placed in such a blind spot are considered necessary.

\section{References}

[1] S.K. Yoon and Y.R. Tak, "Burden, Social support and quality of life of the family caregiver's of hemodialysis patients," Journal of Korean Clinical Nursing Research, vol.20, no.3, pp.395-405, (2014) DOI:10.22650/JKCNR.2014.20.3.395

[2] U.B. Kim, "Study on anxiety of patients who underwent surgery the same day," M.S. thesis, Busan National University, (2000)

[3] H.J. Choi, "The effect preoperative education using moving on anxiety in the patients undergoing total hysterectomy," M.S. thesis, Dongguk University, (2005)

[4] S. Hoermann, S. Doering, R. Richter, M.H. Walter, and G. Schussler, "Patient' need for information before surgery,” Psychother Psycosom Med Psycho, vol.51, no.2, pp.56-61, (2011)

[5] B.H. Kim, Y. Jung, H.J. Kang, and S.W. Lee, "The effect of preoperative teaching on the emotional status of patients prior to surgery," Korean Journal of Adult Nursing, vol.12, no.3, pp.407-417, (2009)

[6] S.K. Kim, "The influence of reducing anxiety of patients who will have gastric polypectomy by producing informative computer animation,” M.S. thesis, KyungHee university, (2003)

[7] M.W. Cho, "The effect of providing a visual information on anxiety and pain in patients with artificial joint replacement," M.S. thesis, Chungnam National University, (2002)

[8] M.G. Kim, "Effect of preoperative information on preoperative anxiety of female aged patients before Total Knee Arthroplasty(TKA)," M.S. thesis, Kosin University, (2008)

[9] J.J. Jeong, "The effect of preoperative nursing information on postoperative anxiety level in patients with open heart surgery," M.S. thesis, Korea University, (2005)

[10] H.S. Ju, "A study on the effects of pre-surgery information services on relief of patients' anxiety and stress depending on patients' types," M.S. thesis, Hanyang University, (2005)

[11] Y.H. Oh, "The effects of surgery information service by media on state anxiety and nursing educational satisfaction in patients with cataract surgery," M.S. thesis, Kosin University, (2016)

[12] C.D. Spielberger, "Anxiety on emotional state, anxiety current trends in theory and research," New York: Academics press, (1972)

[13] J.T. Kim and D.K. Shin, "A study based on the standardization of the STAI for Korea," The New medical journal, vol.21, no.11, pp.69-75, (1978)

[14] M.E. Cline, J. Herman, E.R. Shaw, and D. Morton, "Standardization of the visual analogue scale," Nursing Research, vol.41, no.6, (1992)

[15] M, Sherer, J.E. Maddux, B. Mercandeante, S.P. Dunn, B. Jacobs, and R.W. Rogers, "The self-efficacy scale: Construction \& validation,” Psychological Reports, vol.51, pp.663-671, (1982)

[16] K.Y. Hong, "A study of the relationships among dialysis related knowledge, self efficacy and compliance of patient role behavior in hemodialysis patients," M.S. thesis, Hanyang University, (1999) 